\title{
Chest CT-scan findings of an Iraqi patient with symptomatic covid-19 disease
}

\begin{abstract}
Aamir Jalal Al Mosawi
Advisor in Pediatrics and Pediatric Psychiatry Children Teaching Hospital of Baghdad Medical CityHead, Iraq Headquarter of Copernicus Scientists International Panel Baghdad, Iraq.
\end{abstract}

Corresponding Author: Aamir Jalal Al Mosawi, Advisor in Pediatrics and Pediatric Psychiatry Children Teaching Hospital of Baghdad Medical City, Iraq.

Received date: July 27, 2021; Accepted date: Augusł 23, 2021; Published date: Augusł 31,2021

Citation: Aamir Jalal A, M. (2021). Chest CT-Scan Findings of an Iraqi Patient with Symptomatic Covid-19 Disease. Journal of Clinical Surgery and Research. 2(4); DOI: 10.31579/2768-2757/025

Copyright: (02019 Aamir Jalal Al Mosawi, This is an open-access article distributed under the terms of the Creative Commons Attribution License, which permits unrestricted use, distribution, and reproduction in any medium, provided the original author and source are credited.

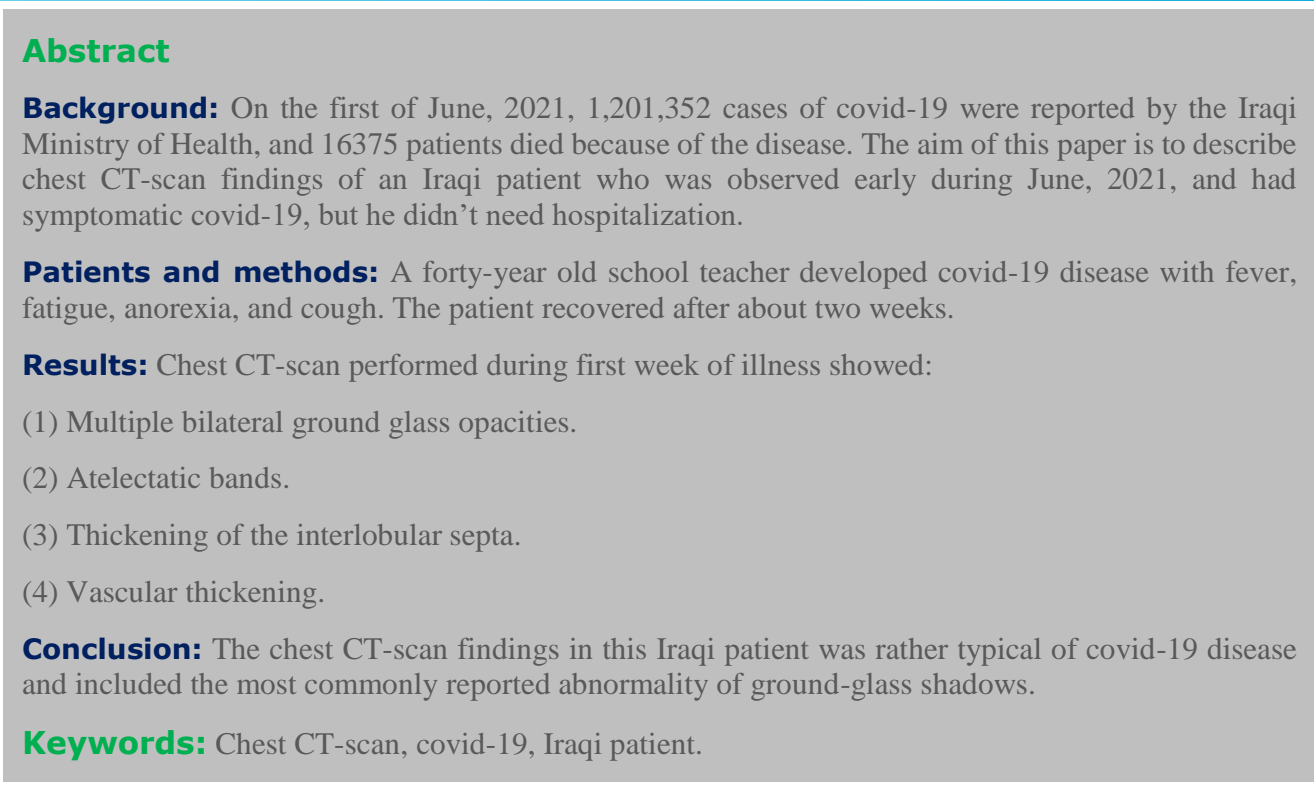

\section{Introduction}

On the first of June, 2021, 1,201,352 cases of covid-19 were reported by the Iraqi Ministry of Health, and 16375 patients died because of the disease [1]. A significant number of covid-19 patients who develop pneumonia were found to have normal chest radiographs. However, Yoon et al (2020) emphasized that most Korea patients with covid-19 pneumonia had abnormalities on chest CT-scan mostly including groundglass opacities with bilateral patchy, confluent or nodular shadows [2].

The aim of this paper is to describe chest CT-scan findings of an Iraqi patient who was observed early during June, 2021, and had symptomatic covid-19, but he didn't need hospitalization.

\section{Patients and methods}

A forty-year old school teacher developed covid-19 disease with fever, fatigue, anorexia, and cough. The patient recovered after about two weeks.

\section{Results}

Chest CT-scan performed during first week of illness (Figure-1) showed:

(1) Multiple bilateral ground glass opacities.

(2) Atelectatic bands.

(3) Thickening of the interlobular septa.

(4) Vascular thickening.

There was no pleural effusion or thickening.

Conclusion: The chest CT-scan findings in this Iraqi patient was rather typical of covid-19 disease and included the most commonly reported abnormality of ground-glass shadows.

\section{Discussion}

Xiang et al (2020) reported the CT-scan findings of fifty three patients (31 males, 22 females; mean age, 53 years) who had Covid-19 pneumonia. They observed the occurrence of ground-glass opacity with 
consolidation in 24 patients $(45.3 \%)$ and pure ground-glass opacity in 28 patients (52.8\%). Crazy-paving occurred in 14 patients (26.4\%), bronchiectasis occurred in 12 patients $(22.6 \%)$, atelectasis occurred in 7 patients $(13.2 \%)$, parenchymal bands occurred in 6 patients $(11.3 \%)$, air bronchogram occurred in 6 patients $(11.3 \%)$, and interlobular thickening occurred in $5(9.4 \%)$.

Xiang et al suggested that most Covid-19 patients who develop pneumonia had abnormalities detectable on chest CT-scan on the time of presentation [3].

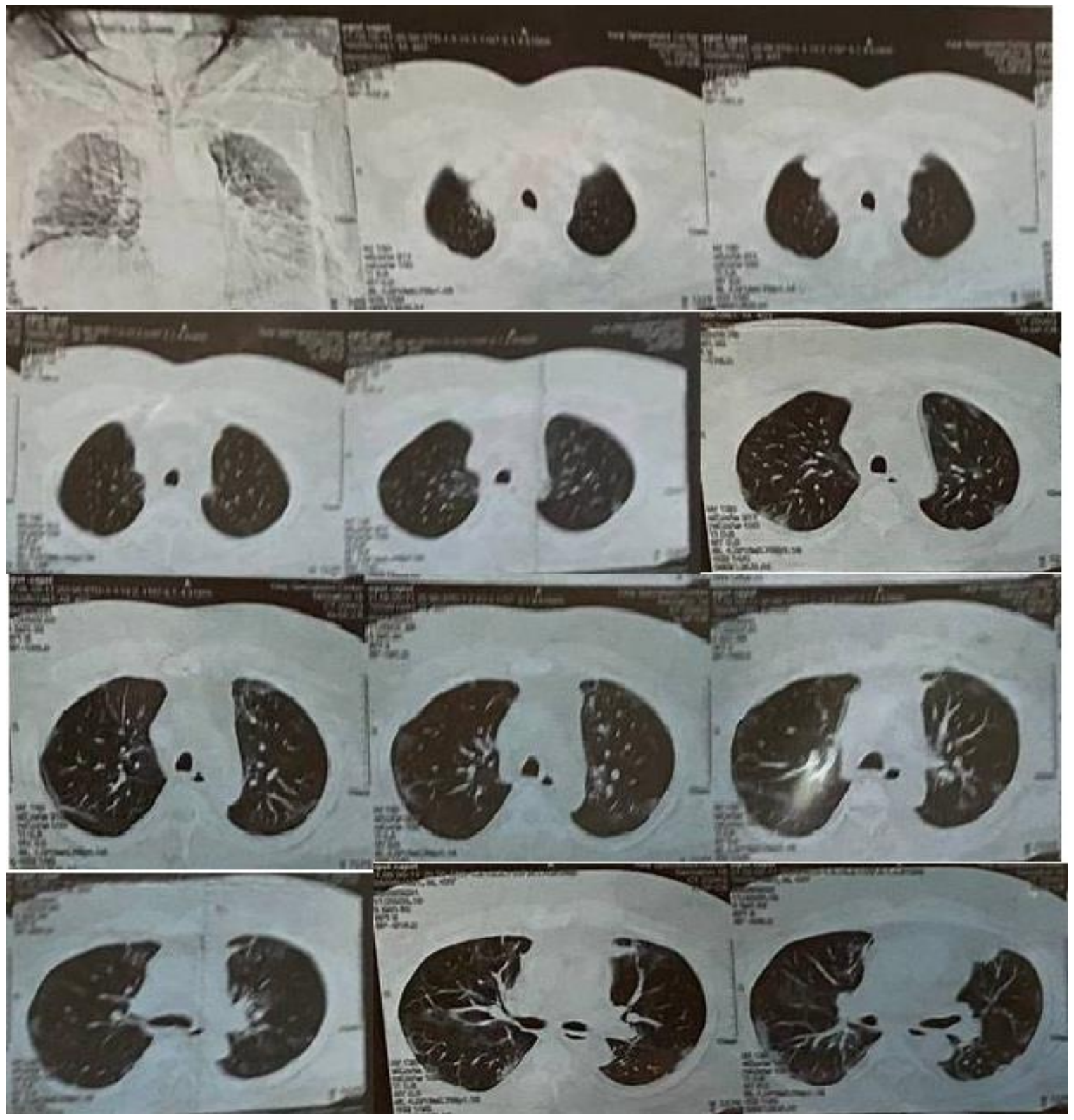

Figure 1A: Chest CT-scan of the patient 


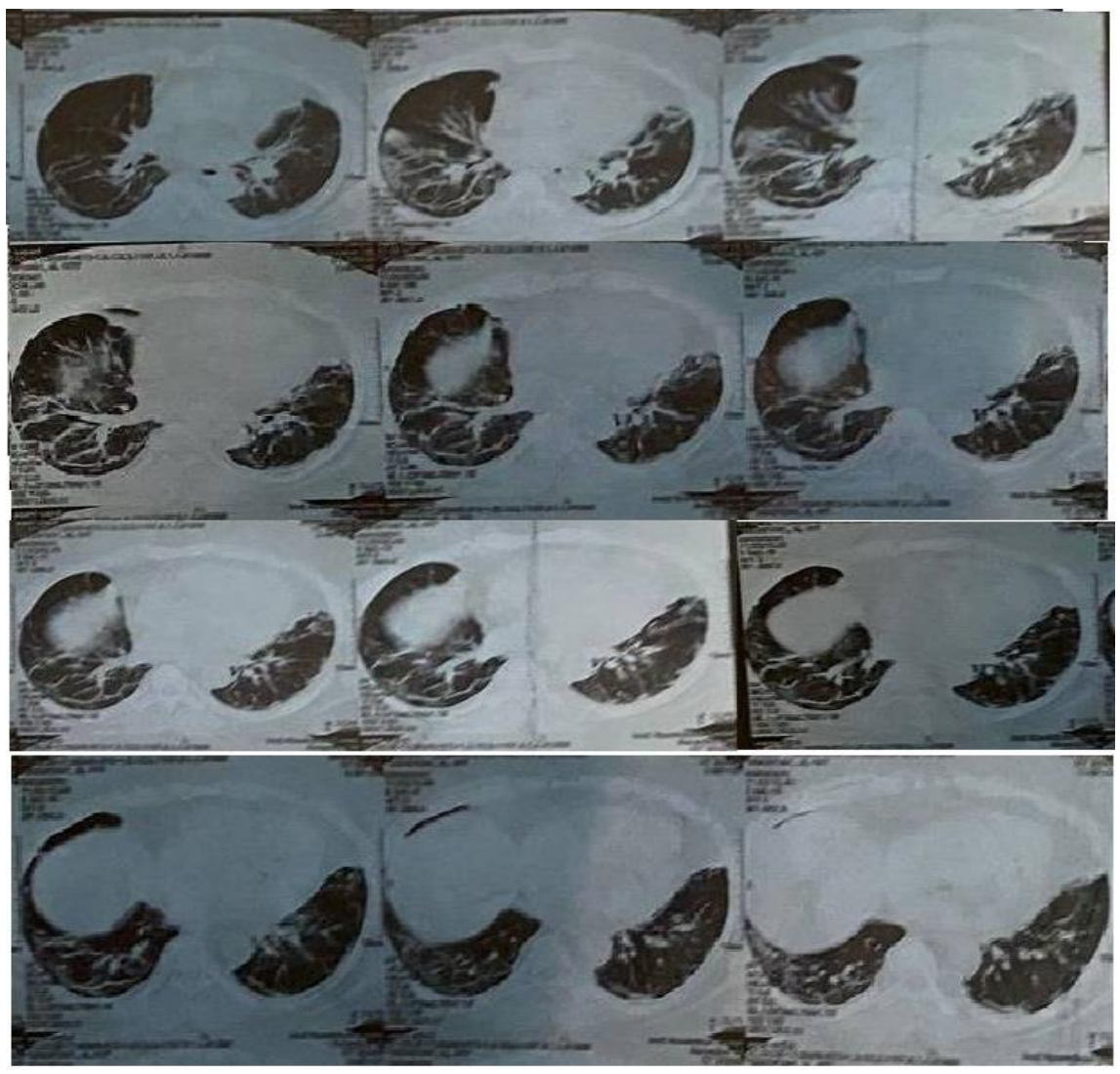

Figure 1B: Chest CT-scan of the patient
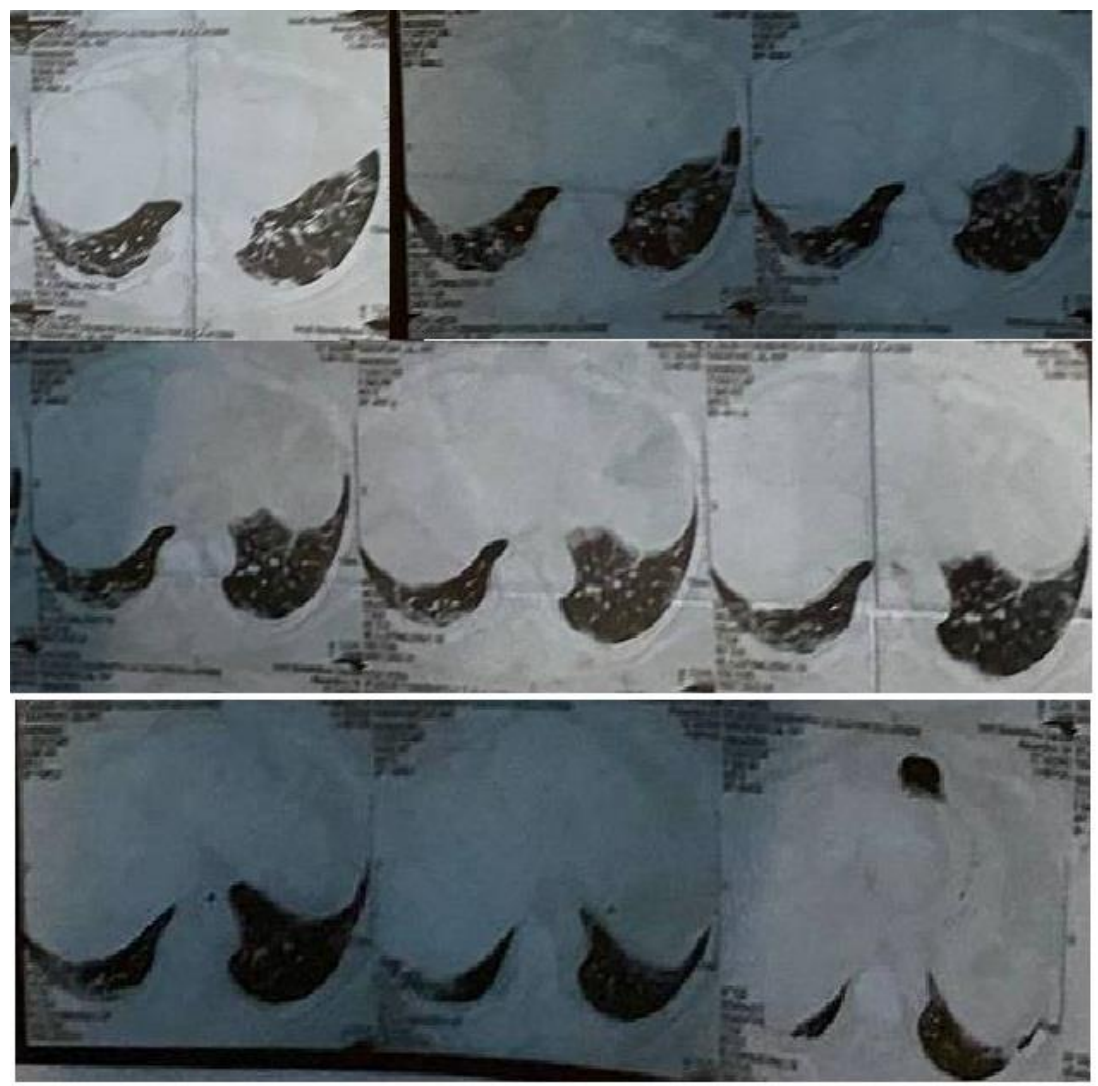

Figure 1C: Chest CT-scan of the patient 
4-Kong et al (2020) reported the CT-scan findings of twenty-two patients hospitalized with Covid-19 disease during the period from January 17, 2020 to February 15, 2020. On presentation nineteen patients had fever and eight patients had cough. Chest CT-scan showed ground-glass opacities in 18 patients, lung consolidation in 7 patients, interlobular septal thickening in five 5 patients, and fibrosis-like stripes in 4 patients.

Wang et al (2021) reported the CT-scan findings of 693 covid-19 patients, including 13 children (51\% males and $49 \%$ females) from 16 hospitals of southeast China during the period from January, 19 to March, 27, 2020.The average age of the patients was 46 years.

Early CT-scan findings included ground-glass-like density shadows (single or multiple nodular, patchy, or flaky) occurred in $47.27 \%$ of the patients, fibrous lesions occurred in $42.60 \%$ of the patients, and microvascular thickening occurred in $40.60 \%$ ) of the patients [4].

\section{References}

1. Al-Mosawi AJ. (2021). Mucormycosis: An emerging dangerous complication of Covid-19 disease. Scholars' Press.

2. Yoon SH, Lee KH, Kim JY, Lee YK, Ko H, Kim KH, Park CM, Kim YH. (2020) Chest Radiographic and CT Findings of the 2019 Novel Coronavirus Disease (COVID-19): Analysis of Nine Patients Treated in Korea. Korean J Radiol. 21(4):494-500.

3. Xiang C, Lu J, Zhou J, Guan L, Yang C, Chai C. (2020) CT Findings in a Novel Coronavirus Disease (COVID-19) Pneumonia at Initial Presentation. Biomed Res Int. 5436025.

4. Kong M, Yang H, Li X, Shen J, Xu X, Lv D. (2020) Evolution of chest CT manifestations of COVID-19: a longitudinal study. J Thorac Dis. 12(9):4892-4907.

5. Wang L, Jiaerken Y, Li Q, et al. (2021) An Illustrated Guide to the Imaging Evolution of Covid in Non-Epidemic Areas of Southeast China. Front Mol Biosci. 8:648180.
This work is licensed under Creative Commons Attribution 4.0 License
To Submit Your Article Click Here: Submit Manuscript

DOI: $10.31579 / 2768-2757 / 025$
Ready to submit your research? Choose Auctores and benefit from:

* fast, convenient online submission

* rigorous peer review by experienced research in your field

* rapid publication on acceptance

* authors retain copyrights

* unique DOI for all articles

* immediate, unrestricted online access

At Auctores, research is always in progress.

Learn more auctoresonline.org/journals/journal-of-clinical-surgery-andresearch 